\title{
The Risks of Payment Systems of Banking Institutions of Ukraine
}

\author{
Natalia V. Trusova ${ }^{1, *}$, Oksana V. Hryvkivska², Leonid V. Melnyk ${ }^{3}$, Olena V. Gerasymova ${ }^{4}$, \\ Maksym A. Tereshchenko ${ }^{5}$
}

\author{
${ }^{1}$ Department of Finance, Banking and Insurance, Dmytro Motornyi Tavria State Agrotechnological University, Melitopol, 72312, \\ Ukraine \\ ${ }^{2}$ Department of Economics, Ecology and Practical Entrepreneurship, European University, Kyiv, 02200, Ukraine \\ ${ }^{3}$ Department of Finance and Economic Security, National University of Water and Environmental Engineering, Rivne, 33028, Ukraine \\ ${ }^{4}$ Department of Finance, Accounting and Taxation, European University, Kyiv, 02200, Ukraine \\ ${ }^{5}$ Department of Entrepreneurship, Trade and Exchange Activities, Dmytro Motornyi Tavria State Agrotechnological University, \\ Melitopol, 72312, Ukraine
}

Received April 16, 2021; Revised June 15, 2021; Accepted June 24, 2021

\section{Cite This Paper in the following Citation Styles}

(a): [1] Natalia V. Trusova, Oksana V. Hryvkivska, Leonid V. Melnyk, Olena V. Gerasymova, Maksym A. Tereshchenko , "The Risks of Payment Systems of Banking Institutions of Ukraine" Universal Journal of Accounting and Finance, Vol. 9, No. 4, pp. 637-652, 2021. DOI: 10.13189/ujaf.2021.090411.

(b): Natalia V. Trusova, Oksana V. Hryvkivska, Leonid V. Melnyk, Olena V. Gerasymova, Maksym A. Tereshchenko (2021). The Risks of Payment Systems of Banking Institutions of Ukraine. Universal Journal of Accounting and Finance, 9(4), 637-652 DOI: 10.13189/ujaf.2021.090411.

Copyright $\odot 2021$ by authors, all rights reserved. Authors agree that this article remains permanently open access under the terms of the Creative Commons Attribution License 4.0 International License

\begin{abstract}
Risks of payment system of banking institutions of Ukraine are considered in this study. Risk events clearly correlate to the effectiveness of network interaction of banking institutions to adapt information technology of payment systems in the payment portfolio of banks when changing operating environment, so mechanism for minimizing their probability has been developed. Economic elements of the mechanism of minimizing the risks of payment systems are identified, which allow forming the planned level of profitability, risk and liquidity of institutions (organizations) within the relevant principles, methods, levers, cash flows in order to respond and adapt to changes in the environment. A methodical approach to assessing the effectiveness of risk management of payment systems of banking institutions, which is from the standpoint of multivariate structuring and a list of their indicators of the microeconomic level, forms an optimal set of tools to minimize the set of risks. Indicators of payment systems of Ukraine are determined, according to the net level of credit risk, liquidity risk, business risk, investment risk, legal risk, operational risk, systemic risk, technological and information security risk. The impulse index of functioning of payment systems of Ukraine is calculated. A neuro-fuzzy model for assessing
\end{abstract}

the individual credit risk of participants - legal entities (users-borrowers) of card payment scoring of a banking institution is developed. The basic criteria for assessing the individual credit risk of a participant-legal entity (user-borrower) by card payment scoring are determined.

Keywords Credit Risk, Liquidity, Economy, Investments, Technological and Information Security

\section{Introduction}

The payment system of Ukraine is an indicator of the economy, one of the priority areas of the development of which is the modernization and improvement of financial instruments, in particular the payment systems of banking institutions. Because the state of the payment market is important for a market economy, and modern paper money cannot meet all the demands of economic entities that arise during their interaction, alternative means of payment is necessary. As a result of evolution and under the influence of digitalization and globalization, money continues to change its appearance and acquire a more 
perfect form - the most suitable for use in payment systems for settlements and payments. This affects the state of money turnover through banking institutions.

At the same time, the rapid and irreversible digitalization of the world has become an objective process of globalization, on which the further development of the financial sector with innovative technologies, ideas and products, impact on the world economy and the functioning and development of global and national payment systems depends. The use of electronic payment systems to ensure the transfer of funds between users of the system in real time via the Internet has become commonplace. In the process of dynamic economic development, their speed, security, convenience, availability and cost are very important for the calculation and transfer of funds. Therefore, the improvement of monetary relations and ensuring the efficient functioning of the national economy, interstate currency settlements directly depend on the effective operation of payment systems of banking institutions. Today, interest in the problems of development of payment systems of any level is constantly growing. Technological innovations are gradually changing payment systems and implementing the modern needs of their users. Due to the dynamics of change, payment service entities, central banks and international organizations try to interact with each other, combining different levels of cooperation (from purely technical organization of money transfer to harmonization of legislation in the field of transfers), which is important for continuous and reliable payment systems of international and domestic importance.

Problems of functioning and further development of payment systems of banking institutions have been studied by O. Baranovskyi [1], Ya. Belinska and N. Kozii [2], N. Dieieva and V. Deleichuk [3], A. Hrytsenko [4], B. Ivasiv [5], B. Vyshyvana and O. Tereshko [6], S. Yehorycheva [7;8]. Such scientists are relevant in the context of money turnover and determining the impact of money transformation processes in electronic payment systems of banking institutions: D. Balto [9], M. Bourreau and M. Verdier [10], J. Cheney, R. Hunt, K Jacob, R. Porter and B. Summers [11], R. Fujii-Rajani [12], M. Galbiati and K. Soramäki [13], P. Haene [14], T. Kokkola [15], C. Lagarde [16], D. Laidler [17], A. Omarini [18], R. Stinneford, L. Brown and C. Davis [19], B. Summers [20], V. Strakharchuk [21].However, the problem of minimizing the risks of payment systems and their functionality in banking institutions deserve special attention in the context of digitalization of the economy and requires further research. The priority of this research is an in-depth study of the functionality of payment systems and the development of a mechanism to minimize their risks, which demonstrates the effectiveness of network interaction of banking institutions to adapt information technology of payment systems in the payment portfolio of banks when changing operating environment.

\section{Materials and Methods}

Payment systems of banking institutions play a crucial role not only in the financial system of an individual country, but also internationally, as they are the movement of money (money turnover) in a globalized world. Due to the dynamics of change, payment service entities, central banks and international organizations try to interact with each other, combining different levels of cooperation (from purely technical organization of money transfer to harmonization of legislation in the field of transfers), which is important for continuous and reliable payment systems of international and domestic importance. At the same time, their effectiveness should be based on appropriate fundamental research of the formation of an effective mechanism for minimizing the risks of payment systems and regulating financial relations in the banking sector. It should be noted that international financial institutions, such as the Bank for International Settlements, the World Bank or the European Central Bank, use the oversight of payment systems both in a particular country and for cross-border payment and settlement systems through a mechanism to minimize the risks of payment systems. It responds quickly to any changes that occur not only due to the actions of banking institutions, but also through the actions of their participants and customers.

The mechanism for minimizing the risks of payment systems allows the formation of the planned level of profitability. This system of interdependent organizational and economic elements, interacts with the objects of the settlement process and the subjects of payment systems, riskiness and liquidity of institutions (organizations) within the relevant principles, methods, levers, cash flows in order to respond quickly and adapt its actions to changes in the external environment. The target of the mechanism for minimizing the risks of payment systems of banking institutions is the formation of favorable organizational and economic conditions for the most profitable and least risky monetary policy to achieve effective functioning of banking institutions, as well as adapting technologies and tools of minimizing the risks of payment systems and payment portfolio to the changes in the operating environment. The economic component of the mechanism, which is based on the process of minimizing the risks of payment systems, aimed at building an optimal payment portfolio and achieving long-term goals of operational activities of banking institutions. Thus, the economic component of the mechanism should form qualitative criteria for highly efficient operation of banking institutions - a clear regulation of methods for minimizing the risks of payment systems and the rational use of monetary resources.

The best method of assessing the economic component of the mechanism of minimizing financial risks of payment systems is a consistent consideration of its elements, the starting point of which is the analysis of the operating environment of banking institutions with in-depth 
assessment of elements of the organizational component (regulation by the National Bank of Ukraine (NBU) of monetary and payment policy of banks on cash acceptance and subsequent transfer, taking into account macroeconomic risk factors of the payment market and micro-level factors - Intrabank monetary-credit and monetary policy of optimal payment portfolio formation, sequence of stages of financial risk management of payment systems).The economic component of the mechanism of minimizing the risks of payment systems includes the following formative elements (technical-technological, spatial-reactionary, reaction-adaptive, control-monitoring and postoperative support), which by a combination of active and passive transactions for payments and transfers of participants in the interaction of the settlement process, taking into account the probability of changing needs of users of payment systems, reduce the impact of risks in a dynamic environment of banking institutions.

Due to the need for improving the mechanism through the dynamism of the external and operational environment of banking institutions, feedback channels are provided, through which it is possible to quickly adjust the elements of the mechanism and identify critical features in their formation. So, an element of reaction-adaptive support, which have been proposed, should combine all the tools of effective functional mechanism - to offer directions to optimize the monetary-credit and monetary policy of banking institutions, to determine adaptive measures to implement anti-crisis measures. Qualitative implementation of this element is one of the main tasks of the mechanism for minimizing risks of payment systems of banking institutions, because it is based on adjusting both the coordinating system of risk minimization and control system of the settlement process in accordance with changes in banks, new methods or valuation tools as well as innovative technologies to provide them. Such improvement should be permanent and comprehensive, so taking into account the possibility of adapting to changes in the external and operational (internal) environment is an integral part of effectively functioning of banking institutions that must rationally use the payment portfolio to achieve strategic goals.

Methodological approach to assessing the effectiveness of risk management of payment systems of banking institutions have been developed (Figure 1), which from the standpoint of multivariate structuring and a list of their indicators of the microeconomic level forms an optimal set of tools to minimize the set of risks. Thus, the settlement risks of banks participating in the payment system are determined by the formula [21]:

$$
\mathrm{P}_{\mathrm{r}}=\mathrm{P}_{\mathrm{er}}+\mathrm{P}_{\mathrm{ar}}+\mathrm{P}_{\text {ret }} \text {, }
$$

where $P_{r}$ is potential risk of the bank-participant of the payment system, $P_{e r}$ is potential emission risk (domestic or international), $P_{a r}$ is potential acquiring risk and $P_{r e t}$ is potential risk of return. The potential risk of the issue is calculated as the total amount for all transactions that the issuer must reimburse to the acquirer, taking into account the number of days required for full settlement with the acquiring bank. The potential risk of acquiring is determined on the basis of the fact that in the event of bankruptcy of the acquirer, his companies must receive funds for all their transactions. The assessment of potential risk is calculated based on the average number of days required for the acquirer's settlements with trade and service enterprises. In this case, it is necessary to take into account the national terms of transfer of funds and the risk category of traders in their areas of activity. The potential risk of returns is determined by calculating the total amount of funds that the acquirer must return to the issuer for unaccepted transactions, taking into account the number of days required for full settlement with the issuing bank. Thus, it should be noted that in today's conditions, payment organizations use a variety of tools to protect against risks.

Given that the level of $n$-th risk of payment systems of banking institutions characterizes the probability of its occurrence due to the impact of a risky event and the consequences of their implementation, it is proposed to calculate the level of efficiency of $n$-th risk of payment system by formula (2) [21]:

$$
\operatorname{Reff} f_{(n-t h R P S)}=\frac{L_{c i m r}}{E_{f f}} \cdot \operatorname{Pr} \text {, }
$$

where Reff(n-thRPS) is the level of efficiency of n-th risk management of the payment system of the banking institution, $L_{\text {cimr }}$ is the level of consequences of the implementation of a risky, $\operatorname{Reff}_{e x}$ is the effectiveness of existing measures to reduce / avoid the consequences of the implementation of a risky event and $P_{r}$ is the probability of a risky event. In addition, the maximum level of efficiency of risk management of the $n$-th payment system of a banking institution should be presented as [21]:

$$
\mathrm{Eff}_{\mathrm{ex}}^{\mathrm{t}} \max \rightarrow\left(\Delta \mathrm{QL}_{\text {cimrto }}{ }^{\mathrm{t}} \leq \Delta \mathrm{Q} \mathrm{L}_{\text {cimr after }}{ }^{\mathrm{t}}\right),
$$

where $\operatorname{Reff}(n-t h R P S)$ is the level of efficiency of n-th risk management of the payment system of the banking institution and $L_{\text {cimr }}$ is the level of consequences of the implementation of a risky. In this case, the level of efficiency of financial risk management of payment systems of banking institutions is determined by formula (4) [21]:

$$
\mathrm{Fr}_{\text {LEPS }}=\frac{\sum(\operatorname{Reff}(\mathrm{Fr})}{\mathrm{n}},
$$

where $F r_{L E P S}$ is the level of efficiency of the financial risk management system of payment systems, $\operatorname{Reff}_{(n-t h R P S)}$ is the level of efficiency of $n$-th risk management of the payment system of the banking institution and $n-$ is the number of risks.

The level of efficiency of management of other risks of payment systems of banking institutions is determined by formula (5) [21]: 


$$
\mathrm{Or}_{\text {LEPS }}=\frac{\sum\left(\mathrm{Reff}_{(\mathrm{Or})}\right)}{\mathrm{n}},
$$

where $O r_{L E P S}$ is the level of efficiency of the management system of other risks of payment systems, $\operatorname{Reff}_{(n-t h R P S)}$ is the level of efficiency of $n$-th risk management of the payment system of the banking institution and $n-$ is the number of risks. In general, the level of efficiency of risk management of payment systems is presented in formula (6) [21]:

$$
\operatorname{Rlm}_{(\mathrm{PS})}=\sqrt[2]{\operatorname{Reff}(\mathrm{Fr}) \cdot \operatorname{Reff(Or})}
$$

where $R \operatorname{lm}_{(P S)}$ is the level of efficiency of the risk management system of payment systems, $F r_{L E P S}$ is the level of efficiency of the financial risk management system of payment systems and $O r_{L E P S}$ is the level of efficiency of the management system of other risks of payment systems. Accordingly, the risk is quantified using formula (7) [22]:

$$
\mathrm{R}=\mathrm{NS} / \operatorname{SorK}=\mathrm{S} /(\mathrm{NS}+\mathrm{S}),
$$

where NS represents factors unfavorable for this measure or key risk indicators that go beyond these limits and $S$ is factors favorable to this measure or key risk indicators contained within the specified limits.

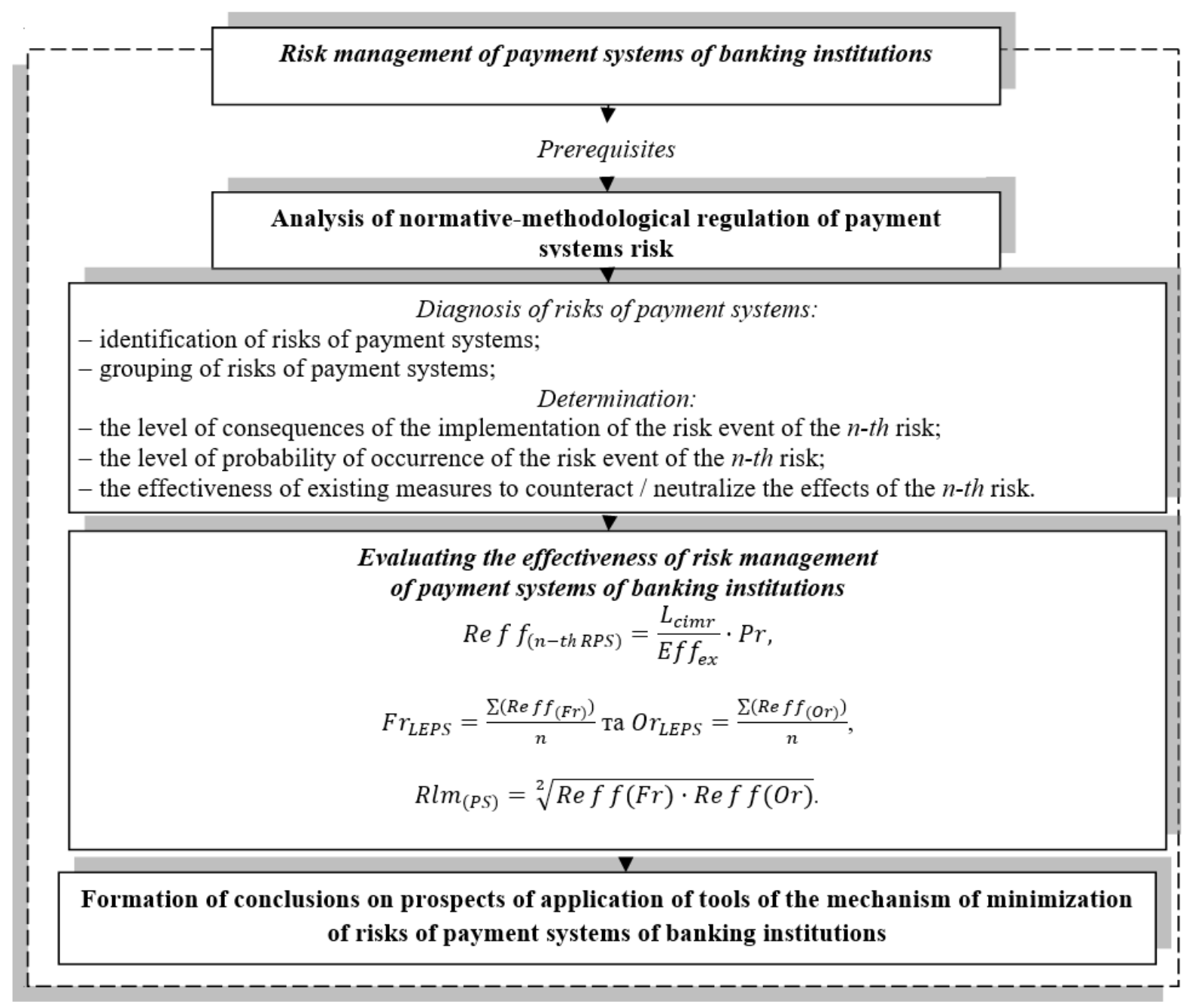

Figure 1. Methodical approach to assessing the effectiveness of risk management of payment systems of banking institutions 


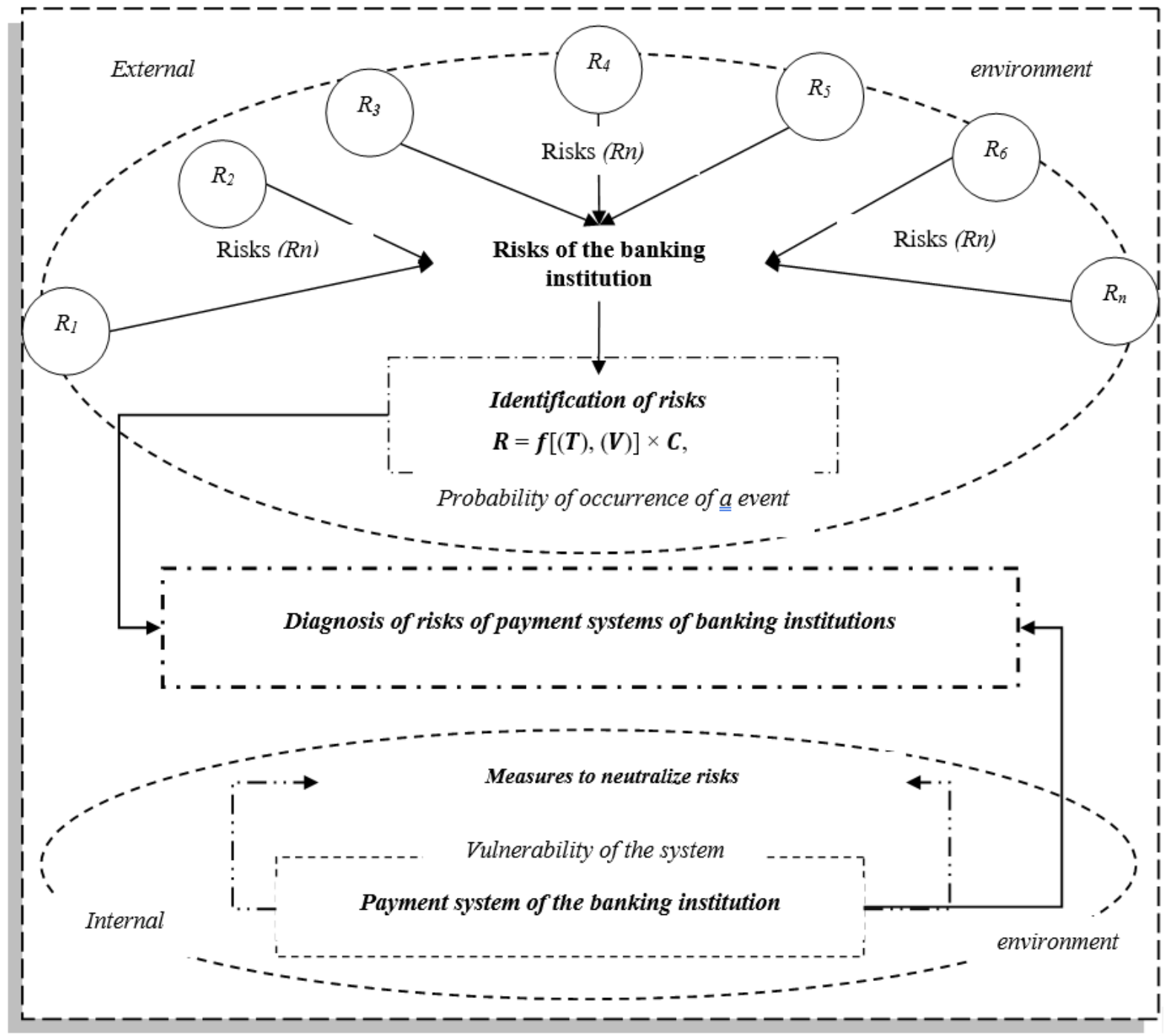

Figure 2. Diagnosis of risks of payment systems of banking institutions

The development of transformational processes of banking services providing new services and qualitatively new forms of interaction with customers necessitates the identification and diagnosis of risks of payment systems of banking institutions, as not only new risks but also modification of traditional risks of payment systems. The algorithm for diagnosing the risks of payment systems of banking institutions is presented in Figure 2. The known threats must be relied upon in the risk identification process However, it is important to consider innovative or new threats for which it makes sense to assume a lack of consolidated protection. Therefore, the assessment of the level of threat for each identified risk should lead to a common indicator of threats to the payment system of banking institutions. Therefore, it is proposed to assess the level of threat for each risk, according to the method of coordination of the threat assessment. At the same time, the probability should be defined and assigned to one of the following categories: low (there is almost no chance for risk realization, but it cannot be said that they do not exist at all); average (the probability of risk realization in these circumstances exists, but the frequency of such risk is low); high (the probability of realization of risk in these circumstances and the frequency of realization of such risk are high).

The stages of the assessment involve determining the following characteristics for each specific threat: overall level of risk; the level of effectiveness of the measures currently taken to prevent or reduce such risk; net level of risk. In accordance with the proposed methodological approach to diagnosing the risks of payment systems of banking institutions, it is proposed to determine the overall risk as follows [22]:

$$
O_{R}=L_{C} \times L_{P},
$$

where $O_{R}$ is overall risk, $L_{C}$ is the level of consequences of the implement at ion of a risky event and $L_{P}$ is the level of probability of a risky event. Accordingly, the matrix and scale of the general level of risk of payment systems of 
banking institutions are presented in Figure 3 and Table 1.

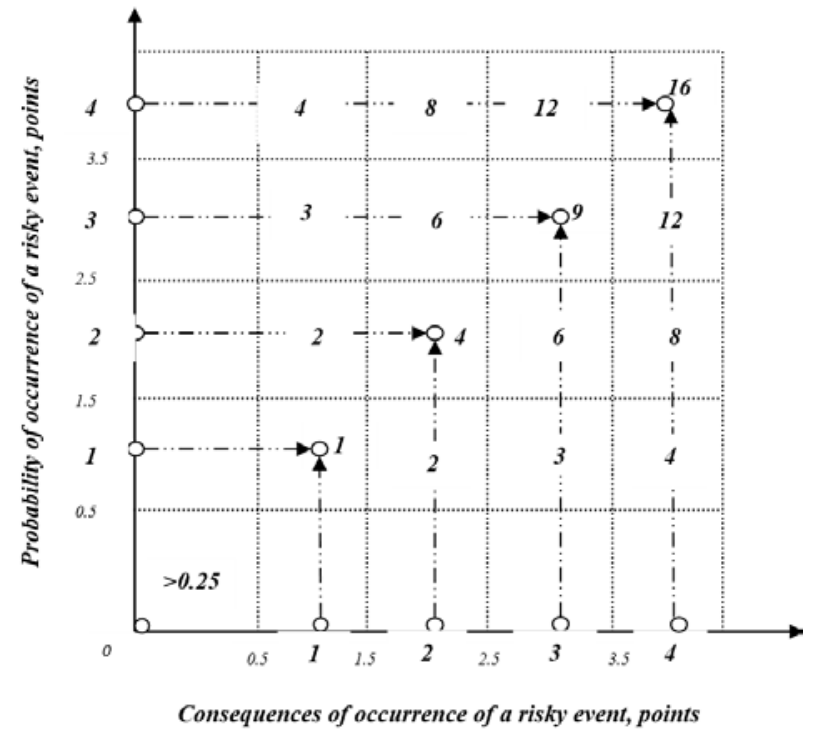

Figure 3. Matrix of the general level of risk of payment systems of banking institutions

Table 1. Scale of the general level of risk of payment systems of banking institutions

\begin{tabular}{|c|c|}
\hline \multicolumn{2}{|c|}{ General level of risk of payment systems of banking institutions } \\
\hline$>0.25$ & Absent (not specified) \\
\hline 1 & $\begin{array}{l}\text { Low (risk will most likely not take place, and in case of } \\
\text { occurrence will have low consequences) (1-3 points) }\end{array}$ \\
\hline 2 & $\begin{array}{l}\text { Average (risk may have place and average consequences) } \\
\text { (4-6 points) }\end{array}$ \\
\hline 3 & $\begin{array}{l}\text { High (risk takes place with high consequences) (7-9 } \\
\text { points) }\end{array}$ \\
\hline 4 & $\begin{array}{l}\text { Critical (risk exists with worst consequences) (10-14 } \\
\text { points) }\end{array}$ \\
\hline
\end{tabular}

After determining the overall level of risk, the current measures taken to prevent or reduce such risk in terms of their effectiveness are assessed, i.e., the net level of risk is determined (formula (9)) [22]:

$$
N_{R}=O_{R} \times E f f_{b m},
$$

where $N_{R}$ is net level of risk, $O_{R}$ is overall risk and $E f f_{b m}$ is the effectiveness of existing measures. Thus, the matrix and scale of the net level of risk of payment systems of banking institutions has the form (Table 2; Figure 4):

Table 2. Scale of net risk level of payment systems of banking institutions

\begin{tabular}{|c|c|}
\hline \multicolumn{2}{|c|}{ Net level of risk of payment systems of banking institutions } \\
\hline$>0.25$ & Absent (not specified) \\
\hline 1 & $\begin{array}{c}\text { Low (risk will most likely not take place, and in case of } \\
\text { occurrence will have low consequences) (1-3 points) }\end{array}$ \\
\hline 2 & $\begin{array}{c}\text { Average (risk may have place and average consequences) } \\
\text { (4-6 points) }\end{array}$ \\
\hline 3 & $\begin{array}{c}\text { High (risk takes place with high consequences) (7-9 } \\
\text { points) }\end{array}$ \\
\hline
\end{tabular}

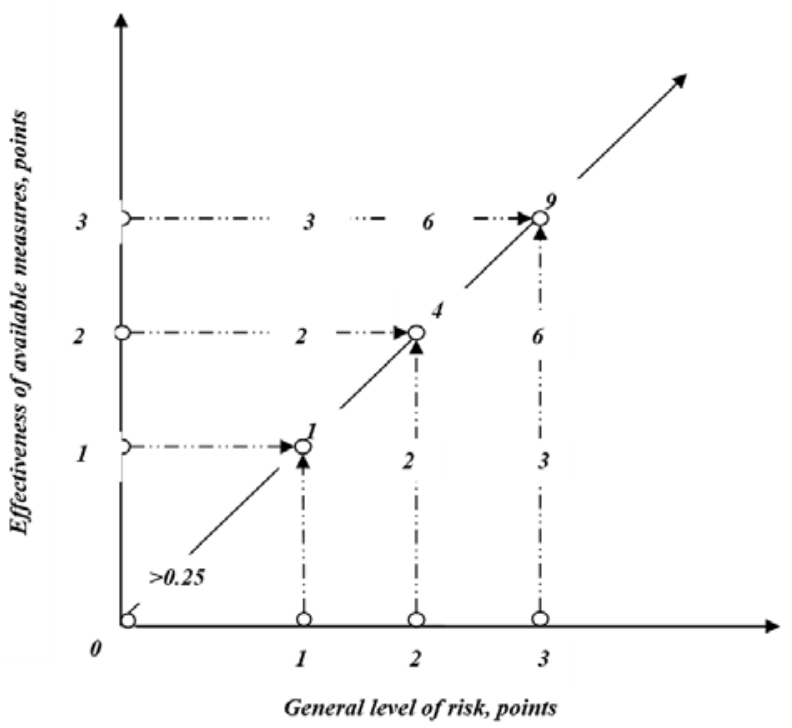

Figure 4. Matrix of net risk level of payment systems of banking institutions

It should be noted that according to the degree of probability of occurrence of events there are:

complete uncertainty (close to 0 degree of predictability (probability) of occurrence of events)), then [23]:

$$
\operatorname{Lim}_{p_{i}}=0, t \rightarrow n,
$$

where $P_{i}$ is predictability of the event $i, t$ is time and $n$ is the final time of event prediction.

full certainty (close to 1 degree of predictability (probability) of occurrence of events), then [23]:

$$
\operatorname{Lim}_{p_{i}}=1, t \rightarrow n,
$$

partial uncertainty (the degree of predictability (probability) of the event is in the range from0 to 1 ), then [23]:

$$
0 \leq \operatorname{Lim}_{p_{i}} \leq 1, t \rightarrow n .
$$

The probability of possible events should be presented as a function of the coexistence of the threat and vulnerability to this threat [23]:

$$
R=\int[(T),(V)] \times C,
$$

where $R$ is risk function, $T$ is factor (variable) associated with the identified threat, $V$ is factor (variable) associated with the identified vulnerability and $C$ is factor associated with the negative consequences caused by the coexistence of threats and vulnerabilities. In other words, risky events occur when the threat has a vulnerability vector and generates negative consequences. Determining the probability of an event is performed by a group $m$ of experts according to the following algorithm, which is as follows [18]: 
1. The probability $c$ is calculated as a weighted average according to the following formula [24]:

$$
C_{i j}=\frac{\sum_{k=1}^{m} \rho_{k} s_{i j}^{k}}{100 \sum_{k=1}^{m} \rho_{k}}
$$

where $\rho_{k}$ is the coefficient of confidence in the $k$-th expert (at the first stage of evaluation, the coefficients of confidence in all experts are the same and equal to1); $S_{i j}^{k}$ is the effectiveness of the $j$-th prevention measure of $\mathrm{n}$-th risk, determined by the $k$-th expert; $m$ is the number of experts.The effectiveness $\left(S_{i j}^{k}\right) j$ of the $j$-th measure to prevent the $n$-th risk is found by each expert on the basis of the scale of effectiveness of measures to neutralize the risks of payment systems of banking institutions. The scale values are defined in the range from 0 to 100 , and they are decomposed in such a way that the probability of vulnerability of such a connection is minimal in the opinion of the expert.

2. The coefficient of trust to the $k$-th expert is adjusted according to the following formula [25]:

$$
\rho_{k}=\frac{1}{T} \sum_{t=1}^{T} \rho_{k}^{t},
$$

where $\mathrm{T}$ is the number of stages of evaluation, $\rho_{k}^{t}=$ $e \frac{\left(R_{i j}-S_{i j}^{k}\right)^{2}}{2 \sigma_{k}}$ is the coefficient of trust in the $k$-the expert at the $t$-th stage of evaluation; $R_{i j}$ is a posteriori effectiveness of the $j$-th measure to prevent the $n$-th risk; $\sigma_{k}$ is the coefficient of forgetting of the $k$-th expert, characterizes the rate of change of confidence in the experts of the decision-making.Thus, the riskiness of the payment system of banking institutions is currently quite relevant, which requires the use of high-tech tools to minimize the risks of the payment system of banking institutions, based on which it is possible to adjust monetary and payment policy of banks in the medium and long term.

\section{Results and Discussion}

The payment system of the banking sector, the main function of which is to make payments, transfers and settlements, includes not only the subjects of the payment market, but also complex technical and technological interaction between them and the payment infrastructure, which, by a set of interconnected elements and between them, affects each other and forms a whole [26]. It should be noted that the volume of payment systems of Ukraine formed by residents in 2019 amounted to 0.53 billion EUR, which is equal to almost $100 \%$ of the turnover of banking institutions in the country. The value of the incoming money supply to Ukraine through the bank payment system of transfers of non-residents (international institutions) amounted to 1.54billion EUR; outgoing cash flow from Ukraine through payment systems of banking institutions amounted to 4.2billion EUR, non-residents - 283.7million EUR. The total volume of card payment system transactions in Ukraine in 2017-2019 increased by 68.3\% (or by 40.7billion EUR including in the form of non-cash payments - by 38.6\% (or by14.0billion EUR) [27-29].

In 2018, there were 42 domestic and international payment systems created by residents and non-residents, as well as 2 systems created by the National Bank. The only important payment system in Ukraine is the Electronic Payment System (EPS NBU). Socially recognized payment systems are Postal transfer, FORPOST, Mastercard, Visa. Six more payment systems fell into the category of important: InterPay-Service, City 24, Financial World (Ukrainian payment system), MoneyGram, INTELEXPRESS, and RIA. On the Ukrainian market there is the world's largest in terms of the number of payment cards issued - the Chinese international payment system UnionPay International. In Ukraine, there is a joint oversight between the Central Bank of Belgium and the National Bank of Ukraine on the MasterCard payment system, which performs about $70 \%$ non-cash card transactions in Ukraine. However, in certain forms of active-passive operations, the risks of payment systems are identified, which have the characteristic features of threats to corporate banking operations under the influence of environmental factors. Thus, the results of diagnosing the risks of payment systems of banking institutions of Ukraine (Figure 5-12) show that the highest risks belong to the payment system "Oshchad 24", the values of which during the analyzed period fluctuated within 0.710 (net level of credit risk) in 2015 and0.561 ((net level of storage risk and investment risks) in 2019, which is largely attributed to the low level of fulfillment of its financial obligations and the availability of financial assets of the payment organization. 


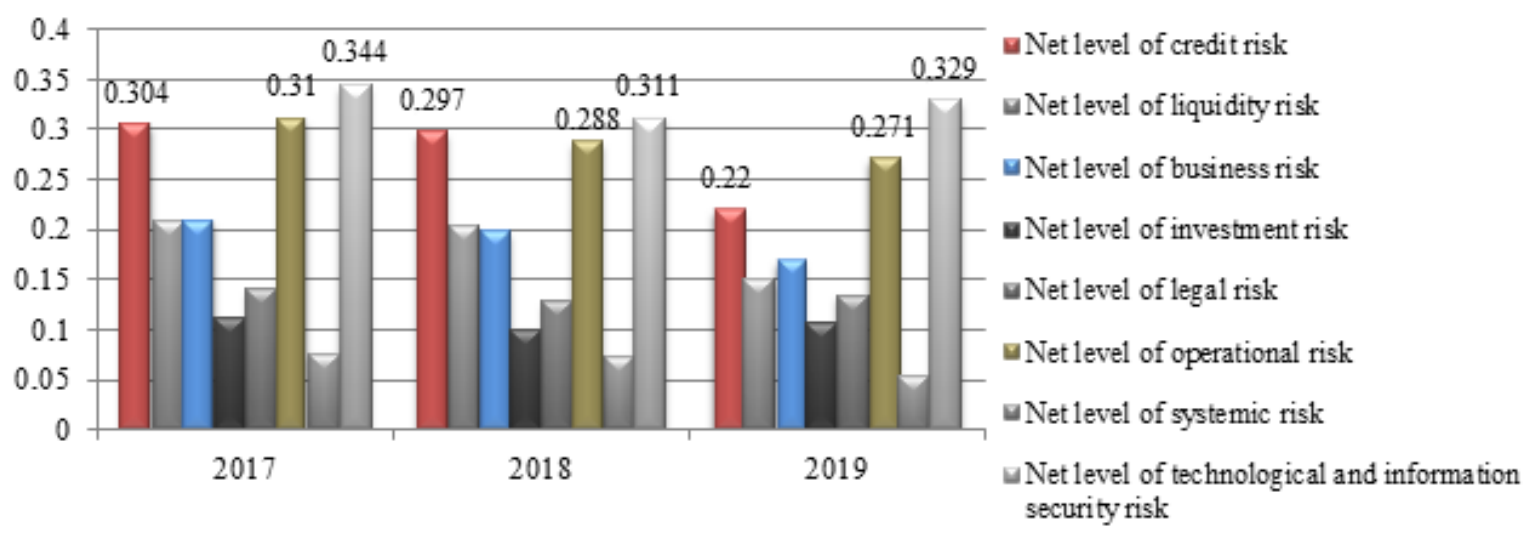

Figure 5. Risks of the payment system “Google Pay” in Ukraine for 2017-2019

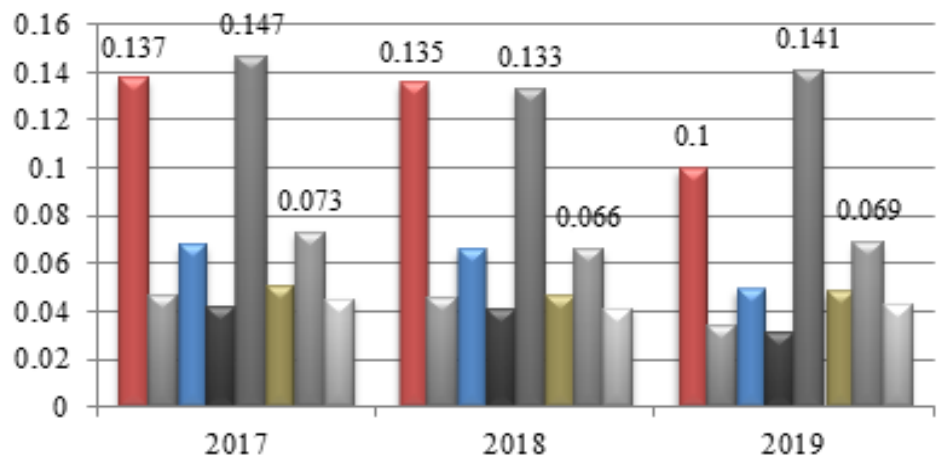

$\square$ Net level of credit risk

$\square$ Net level of liquidity risk

$\square$ Net level of business risk

a Net level of investment risk

$\square$ Net level of legal risk

$\square$ Net level of operational risk

$\square$ Net level of systemic risk

$\square$ Net level of technological and information security risk

Figure 6. Risks of the payment system “Monobank” in Ukraine for 2017-2019

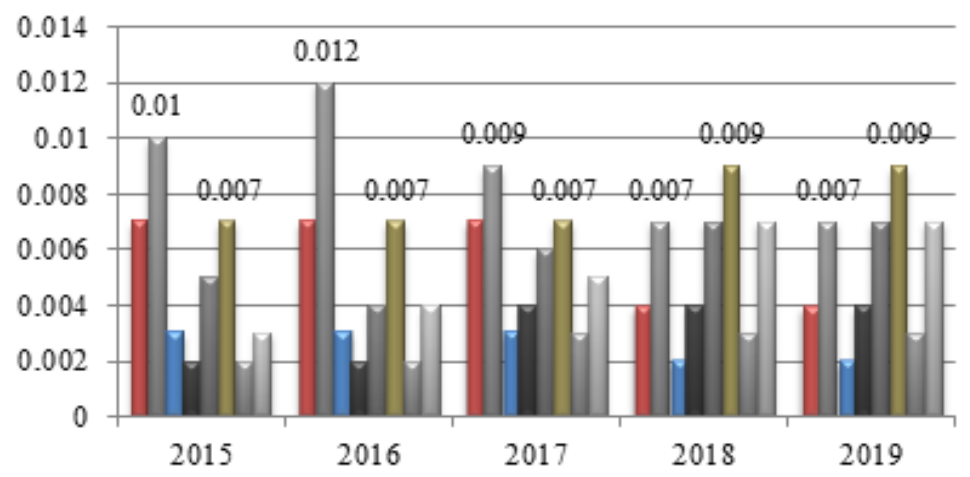

- Net level of credit risk

$\square$ Net level of liquidity risk

Net level of business risk

Net level of investment risk

$\square$ Net level of legal risk

$\square$ Net level of operational risk

$\square$ Net level of systemic risk

$\square$ Net level of technological and information security risk

Figure 7. Risks of the payment system "Mastercard” in Ukraine for 2017-2019 


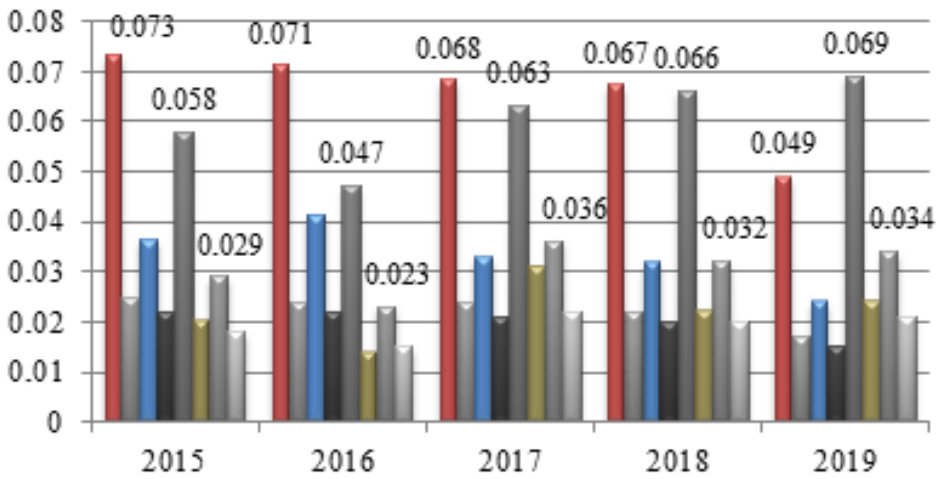

Figure 8. Risks of the payment system "Visa" in Ukraine for 2017-2019

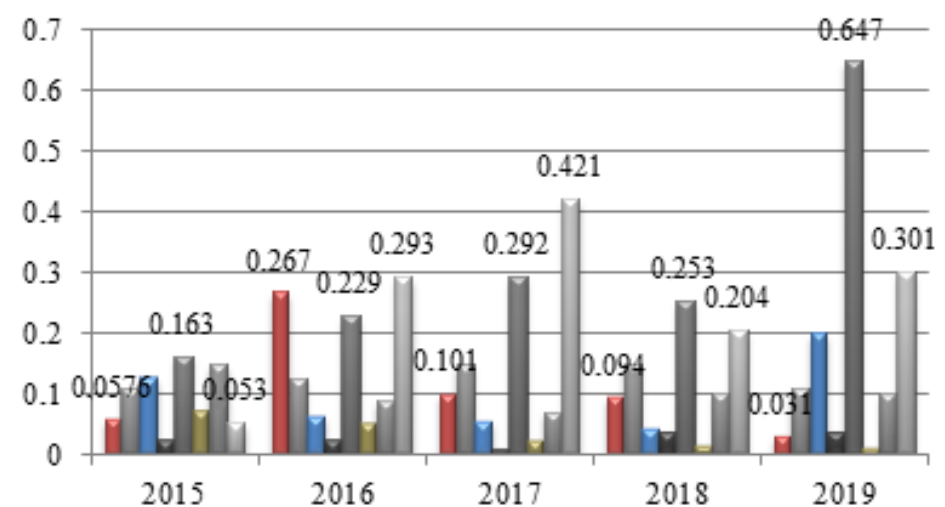

$\square$ Net level of credit risk

$\square$ Net level of liquidity risk

$\square$ Net level of business risk

Met level of investment risk

$\square$ Net level of legal risk

$\square$ Net level of operational risk

$\square$ Net level of systemic risk

$\square$ Net level of technological and information security risk a Net level of credit risk

$\square$ Net level of liquidity risk

$\square$ Net level of business risk

wet level of investment risk

- Net level of legal risk

$\square$ Net level of operational risk

$\square$ Net level of systemic risk

$\square$ Net level of technological and information security risk

Figure 9. Risks of the payment system "Prostir” in Ukraine for 2017-2019

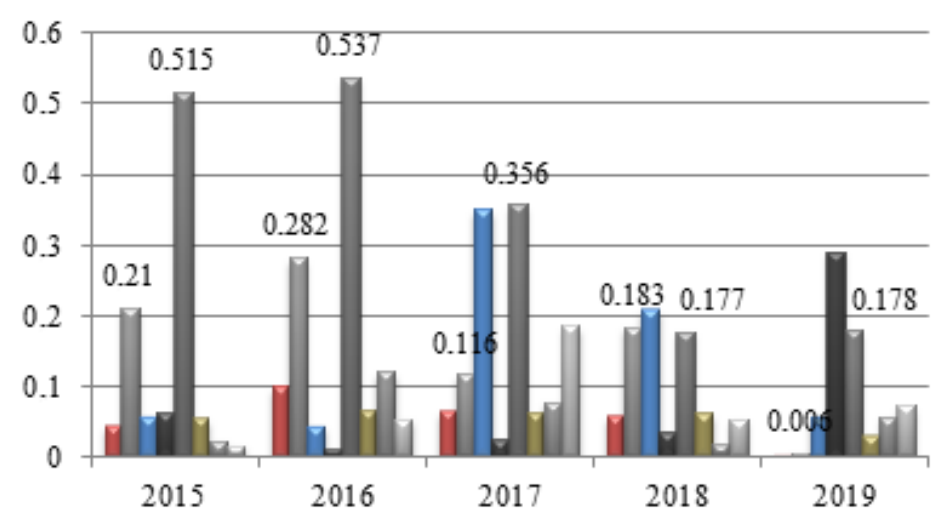

Figure 10. Risks of the payment system "Privat 24” in Ukraine for 2017-2019
Net level of credit risk

$\square$ Net level of liquidity risk

Net level of business risk

Net level of investment risk

Net level of legal risk

$\square$ Net level of operational risk

$\square$ Net level of systemic risk

$\square$ Net level of technological and information security risk 


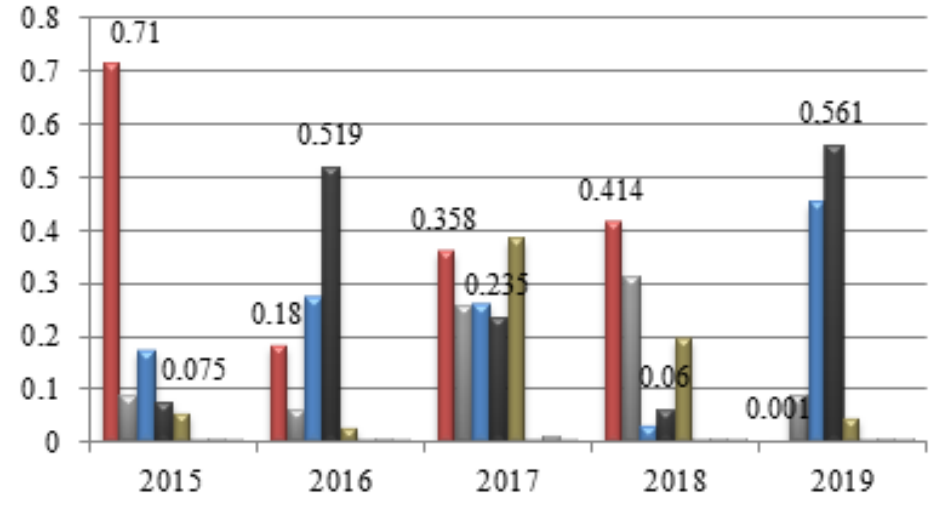

Figure 11. Risks of the payment system “Oshchad 24” in Ukraine for 2017-2019

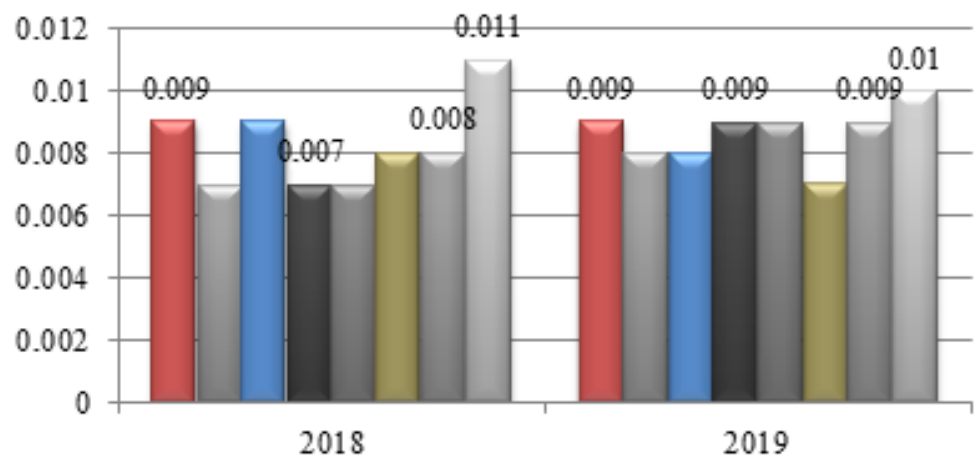

$\square$ Net level of credit risk

$\square$ Net level of liquidity risk

$\square$ Net level of business risk

wet level of investment risk

$\square$ Net level of legal risk

$\square$ Net level of operational risk

$\square$ Net level of systemic risk

$\square$ Net level of technological and information security risk

Figure 12. Risks of the payment system “Apple Pay” in Ukraine for 2017-2019

Quite a high level of risk is observed in the domestic payment system "Prostir", in particular, 0.576 (net level of credit risk) in 2015 and0.647 net level of legal risk) in 2019, i.e., there is a low level of legal regulation, change or unpredictable application of legal provisions. The highest risks of the Google Pay payment system are: credit risk, liquidity risk, business risk, operational risk and technological and information security risk. The reliability and security of the Monobank payment system is largely reduced under the influence of credit and legal risks, which state the results of diagnosing the risks of payment systems of banking institutions, indicating the low effectiveness of risk management policy. Among the risks of the payment system "Privat 24", which reduce the security of the use of this payment system, the liquidity risk and legal risk is worth noting. The most secure payment systems currently in operation are Visa, Apple Pay and Mastercard.

The financial business sector is too sensitive to changes and needs of potential customers, including changes in the payment market. Therefore, payments by payment systems are rapidly changing, creating new demands on the payment services market, leading to an increase in their varieties, which allow the use of gross (gross settlement system), net (net settlement system) and mixed payment systems (hybrid system), differing in speed and immediate payment. Thus, in the gross system, payments are made separately for each payment, and in the net - at the end of a certain period on the calculated balance of sent and received payments. If more detailed gross settlement system is considered, then the speed and order of calculations are important for this system. Thus, in RTGS-systems (real-time gross settlement) settlements are made for each payment immediately, and in end-of-day gross settlement systems - with deferred payment. In net systems there is a multilateral net settlement system and deferred net settlement system. Net settlements can also be deferred and take place in deferred net settlement systems [30].

It should be noted that gross systems are more expensive for participants, given the constantly required amount of funds for credit settlements. However, the net system does not require funds for each transaction and is less costly, but at the same time, riskier compared to the gross system (lack of information on the balance of money for transfer or settlement at the end of the set period). To determine the risk of the payment system, factor model and proposed a comprehensive Index of Impulse Functioning of Payment System ( $I_{i f}^{p s}$ ) have been developed, which allows determining the criteria of operation and reliability of the system to ensure efficient cash flow on the basis of 
oversight. In developing the proposed methodology, the survey method was used - users of payment system services were interviewed and 100 questionnaires were processed in 2015-2019. Questions are developed and offered to clients:

Questionnaire 1. Among the factors - Security, Convenience, Speed, Cost, Reliability - give priorities to their importance in the activities of the payment system in the ranking from 1 to 5 points.

Questionnaire 2. Among the proposed payment systems, provide an assessment of the payment system on the following factors - Security, Convenience, Speed, Cost, Reliability - which must meet the payment system or service from 0 to 5 points.

Based on the results of processing the personal data, the coefficients of weight of the factors are determined and $I_{i f}^{p s}$, is calculated (formula (16)) [30]:

$$
\begin{aligned}
I_{i f}^{p s}= & 0.323 \times S_{p s}+0.274 \times R_{p s}+0.156 \times C_{t r}+ \\
& 0.101 \times E u_{p s}+0.146 \times S p^{t r},
\end{aligned}
$$

where $I_{i f}^{p s}$ is Index of Impulse Functioning of Payment System, $S_{p s}$ is security in the payment system, $R_{p s}$ is reliability of the payment system, $C_{t r}$ is the cost of transactions, $E u_{p s}$ is the ease of use of the payment system and $S p^{t r}$ is the speed of payment (transaction) in the system.

Criteria for user evaluation of payment system services from «0» to «5» were as follows: «4-5» - a high level of functioning of the payment system; «3-4» - the average level of functioning of the payment system; «2-3» - below average; «1-2» - a low level of functioning of the payment system, «0-1» - the user will not use the payment system. The calculation $I_{i f}^{p s}$ is given in Table 3.

The National Bank of Ukraine has identified a list of systemically important, socially important and important payment systems in Ukraine. The distribution of payment systems by categories of importance is carried out by the regulator in accordance with international practice to bring the activities of significant payment systems, which occupy a significant market share, in line with international standards of oversight.

Thus, the results of monitoring the activities of payment systems in 2019 indicate the following:

1. The only systemically important payment system in Ukraine, as in previous years, remains the NBU's electronic payment system (EPS).

2. The list of payment systems included in the category of socially important payment systems in Ukraine has not changed compared to 2018. The status of socially important payment systems was confirmed by five payment systems: MasterCard, MasterCard International Incorporated, USA; Visa, Visa International Service Association, USA; Western Union, Western Union Financial Services Inc. United States / Western Union Network, SAS, France; "FORPOST" (today - NovaPay), LLC "Post Finance"; "Postal transfer”, PJSC “Ukrposhta”; since November 2017, the payment systems "Monobank”, Universal Bank and "Google Pay”, Google; since May 2018, the payment system "Apple Pay”, Oshchadbank has started working.

3. In the category of important payment systems in comparison with 2018, one payment system "InterPayService" has lost the status of an important payment system. At the same time, this category includes the FLASHPAY payment system. In general, the important payment systems included: "Financial World”, LLC "Ukrainian Payment System”; MoneyGram, Money Gram Payment Systems Inc. USA; City 24, Phoenix Financial Company LLC; "FLASHPAY", PJSC "Family Bank"; RIA, Continental Exchange Solutions Inc, USA; INTELEXPRESS, JSC Microfinance Organization “Intellexpress”, Georgia.

The National Bank imposes stricter requirements on payment organizations that are included in the categories of importance in terms of management and organization of activities, access and participation in the payment system, risk management system, final settlement, cyber resilience and business continuity management. In addition, in January 2020, the National Bank for the first time established the procedure and criteria for identifying significant operators of payment infrastructure services. According to the results of monitoring in 2019, significant operators of payment infrastructure services are PJSC "Ukrainian Processing Center" and LLC "TAS LINK". The National Bank has established stricter requirements for ensuring the continuity of activities for such significant service operators of payment infrastructure, which are based on international oversight standards. Thus, today the highest Index of the momentum of the payment system functioning $\left(\boldsymbol{I}_{\boldsymbol{i f}}^{\boldsymbol{p s}}\right)$ belongs to the payment systems (EPS) of the NBU, Visa (Visa), Western Union, Apple Pay and MasterCard. National payment system Prostir at this stage of its development is significantly inferior to international card payment systems. The obtained results are reflected in the volumes and quantities of payment transactions conducted in these systems. 
Table 3. Index of the momentum of the payment system functioning $\left(I_{i f}^{p s}\right)$ in 2015-2019

\begin{tabular}{|c|c|c|c|c|c|}
\hline \multirow{2}{*}{ Payment systems in Ukraine } & \multicolumn{5}{|c|}{ Index of the momentum of the payment system functioning $\left(I_{i f}^{p s}\right)$} \\
\hline & 2015 & 2016 & 2017 & 2018 & 2019 \\
\hline (EPS) NBU (NBU electronic payment system) & 3.68 & 3.98 & 4.01 & 4.12 & 4.35 \\
\hline MasterCard & 3.33 & $3, .64$ & 3.78 & 3.88 & 3.86 \\
\hline Visa & 3.25 & 3.49 & 3.58 & 3.87 & 4.27 \\
\hline Western Union & 3.27 & 3.55 & 3.61 & 3.90 & 4.18 \\
\hline FORPOST & 2.02 & 2.13 & 2.38 & 2.41 & 2.69 \\
\hline Postal transfer & 2.85 & 2.88 & 2.89 & 2.90 & 2.93 \\
\hline InterPayService & 2.38 & 2.27 & 1.05 & - & - \\
\hline FLASHPAY & - & - & - & 2.50 & 2.69 \\
\hline Financial World & 2.89 & 2.86 & 2.87 & 2.89 & 2.90 \\
\hline MoneyGram & 3.01 & 3.11 & 3.28 & 3.33 & 3.48 \\
\hline City 24 & 3.08 & 3.18 & 3.22 & 3.25 & 3.29 \\
\hline RIA & 3.10 & 3.11 & 3.14 & 3.19 & 3.22 \\
\hline INTELEXPRESS & 3.13 & 3.18 & 3.23 & 3.26 & 3.28 \\
\hline Prostir & 2.14 & 2.20 & 2.34 & 2.52 & 2.69 \\
\hline Privat 24 & 3.24 & 3.39 & 3.41 & 3.54 & 3.75 \\
\hline Oshchad 24 & 2.05 & 2.18 & 2.42 & 2.49 & 3.14 \\
\hline Monobank (with 11.2017) & - & - & 3.48 & 3.52 & 3.69 \\
\hline Apple Pay (with 05.2018) & - & - & - & 3.94 & 4.04 \\
\hline Google Pay (with 11.2017) & - & - & 3.38 & 3.43 & 3.40 \\
\hline
\end{tabular}

Note: for the second half of 2018 (since its operation in Ukraine).

It is considered to use a neuro-fuzzy technology in the implementation of bank payment scoring in the probability of individual credit risk of the participant-legal entity (user-borrower), in addition to the bank and the budgetary institution. To build a neuro-fuzzy model, the following factors were chosen: total liquidity ratio; instant liquidity ratio; current liquidity ratio; asset mobility ratio; cash flow ratio; coefficient of financial stability of the participant-legal entity (user-borrower), coefficient of independence; the ratio of own working capital. As the values of the integrated assessment of the level of individual credit risk of the banking institution in relation to the participant-legal entity (user-borrower) ( $y$ ), chosen 0 - if the terms of the credit agreement between the borrower and the bank are met (there is no risk) and 1 - if the terms of the credit agreement are not met (maximum risk) [31]. Input data for modeling the individual credit risk of participants-legal entities (users-borrowers) of card payment scoring of JSC CB "PRIVATBANK" are formed from 12 credit agreements.

The interdependence of factors-indicators of the financial condition of participants-legal entities (users-borrowers) of card payment scoring is calculated using the pairwise correlation coefficient. Thus, paired factors, both total and current liquidity ratios, total liquidity ratio and working capital ratio, current liquidity ratio and working capital ratio, asset mobility ratio and independence ratio of participants-legal entities (users-borrowers) have a high level of linear dependence. Therefore, to build a neuro-fuzzy model for assessing the level of individual credit risk of participants-legal entities (users-borrowers) of card payment scoring of a banking institution (JSC CB "PRIVATBANK"), the following factors are given: $x_{1}-$ instant liquidity ratio; $x_{2}$ - current liquidity ratio; $x_{3}$ - asset mobility ratio; $x_{4}$ - cash flow ratio; $x_{5}$ - coefficient of financial stability. In this case, the class of the participant-legal entity (user-borrower) is determined by calculating the integrated indicator of card payment scoring using a multifactor discriminant model (formula (17)) [32]:

$$
Z=a_{1} K_{1}+a_{2} K_{2}+a_{3} K_{3}+\ldots+a_{n} K_{n}-a_{0},
$$

where $Z$ is an integral indicator; $K_{1}, K_{2}, K_{3} \ldots K_{n}$ are financial ratios determined on the basis of the financial statements of the debt or - a legal entity for a large or medium-sized enterprise; $a_{1}, a_{2}, a_{3} \ldots a_{n}$ are parameters that are determined taking into account the weight and bit size of financial ratios and are updated annually by the NBU on the basis of financial statements of debtors - legal entities; $a_{0}$ is a free member of the discriminant model, the values of which are updated annually by the NBU. With the help of an integrated indicator, the class of the debtor a legal entity (from1 to 9) is determined. In turn, the state of debt service depends on the number of calendar days of delay: "high" (from 0 to 7 days of delay); "good" (from8 to 
30 days of delay); "satisfactory" (from 31 to 90 days of delay); "weak" (from91 to 180 days of delay); "unsatisfactory" (more than 180 days of delay). Based on the class of the participant-legal entity (user-borrower) and the state of debt service, the banking institution distributes the amount of credit debt by the following categories of quality: I (highest) - no risk or the risk is minimal; II moderate risk; III - significant risk; IV - high risk; V (lowest) - realized risk. Card payment scoring of participants-legal entities (users-borrowers), formula (18)
[32]:

$$
y=f\left(x_{1}, x_{2}, x_{3}, x_{4}, x_{5}\right),
$$

The calculation of the value of individual credit risk begins with the formation of a fuzzy production base of criteria, which is a set of fuzzy expert-linguistic rules such as "IF-SO" and connects the linguistic estimates of input variable $\left(x_{1}, x_{2}, x_{3}, x_{4}, x_{5}\right)$ and output variable $y$ [6]. Linguistic estimates will be obtained based on the information in Tables 4-6.

Table 4. Input data for modeling the individual credit risk of the participant-legal entity (user-borrower) by card payment scoring of JSC CB "PRIVATBANK"

\begin{tabular}{|c|c|c|c|c|c|c|c|c|c|}
\hline № & $\begin{array}{c}\text { Total } \\
\text { liquidity } \\
\text { ratio }\end{array}$ & $\begin{array}{c}\text { Instant } \\
\text { liquidity } \\
\text { ratio }\end{array}$ & $\begin{array}{c}\text { Current } \\
\text { liquidity } \\
\text { ratio }\end{array}$ & $\begin{array}{c}\text { Asset } \\
\text { mobility } \\
\text { ratio }\end{array}$ & $\begin{array}{c}\text { Cash flow } \\
\text { ratio }\end{array}$ & $\begin{array}{c}\text { Financial } \\
\text { stability } \\
\text { ratio }\end{array}$ & $\begin{array}{c}\text { Independence } \\
\text { ratio }\end{array}$ & $\begin{array}{c}\text { Working } \\
\text { capital ratio }\end{array}$ & $y$ \\
\hline 1 & $(1)$ & $(2)$ & $(3)$ & $(4)$ & $(5)$ & $(6)$ & $(7)$ & $(8)$ & \\
\hline 2 & 0.40 & 0.01 & 0.24 & 0.10 & -0.27 & 0.63 & 0.58 & -0.60 & 1 \\
\hline 3 & 0.25 & 0.00 & 0.22 & 1.70 & 0.79 & -3.11 & -1.33 & -0.75 & 1 \\
\hline 4 & 0.95 & 0.00 & 0.73 & 18.62 & 1.35 & -0.11 & -10.41 & -0.37 & 1 \\
\hline 5 & 0.38 & 0.00 & 0.21 & 0.47 & -3.77 & -0.02 & -6.00 & -0.62 & 1 \\
\hline 6 & 0.94 & 0.00 & 0.74 & 1.20 & 0.73 & 0.36 & 1.80 & -0.06 & 0 \\
\hline 7 & 7.15 & 0.37 & 3.10 & 0.06 & 0.51 & 0.98 & 0.02 & 6.15 & 0 \\
\hline 8 & 7.79 & 0.41 & 2.71 & 0.51 & 19.04 & 0.92 & 0.08 & 6.79 & 0 \\
\hline 9 & 0.20 & 0.01 & 0.04 & 0.10 & -17.43 & 0.81 & 0.23 & -0.08 & 0 \\
\hline 10 & 1.07 & 0.08 & 0.82 & 2.15 & -21.87 & 0.31 & 2.35 & 0.05 & 0 \\
\hline 11 & 1.02 & 0.07 & 0.06 & 0.66 & 5.99 & 0.10 & 9.22 & 0.02 & 0 \\
\hline 12 & 1.39 & 0.02 & 1.39 & 0.12 & 11.01 & 0.92 & 0.99 & 0.39 & 0 \\
\hline
\end{tabular}

Table 5. Coefficients of pair correlation of indicators of creditworthiness of participants-legal entities (users-borrowers) by card payment scoring of JSC CB "PRIVATBANK"

\begin{tabular}{|c|c|c|c|c|c|c|c|c|}
\hline & $(1)$ & $(2)$ & $(3)$ & $(4)$ & $(5)$ & $(6)$ & $(7)$ & $(8)$ \\
\hline$(1)$ & 1.000 & 0.618 & 0.949 & -0.192 & 0.181 & 0.458 & 0.143 & 0.996 \\
\hline$(2)$ & 0.618 & 1.000 & 0.676 & -0.124 & -0.086 & 0.284 & 0.118 & 0.618 \\
\hline$(3)$ & 0.949 & 0.676 & 1.000 & -0.135 & 0.168 & 0.505 & 0.072 & 0.949 \\
\hline$(4)$ & -0.192 & -0.124 & -0.135 & 1.000 & 0.440 & -0.052 & -0.715 & -0.192 \\
\hline$(5)$ & 0.181 & -0.086 & 0.168 & 0.440 & 1.000 & 0.210 & 0.196 & 0.181 \\
\hline$(6)$ & 0.458 & 0.284 & 0.505 & -0.052 & 0.210 & 1.000 & 0.058 & 0.458 \\
\hline$(7)$ & 0.143 & 0.118 & 0.072 & -0.715 & 0.196 & 0.058 & 1.000 & 0.143 \\
\hline$(8)$ & 0.996 & 0.618 & 0.949 & -0.192 & 0.181 & 0.458 & 0.143 & 1.000 \\
\hline
\end{tabular}

Table 6. Criteria for variables $x_{1}, x_{2}, x_{3}, x_{4}, x_{5}$ of individual credit risk of participants-legal entities (users-borrowers)

\begin{tabular}{|c|c|c|c|c|c|}
\hline Criterion title & $x_{1}$ & $x_{2}$ & $x_{3}$ & $x_{4}$ & $x_{5}$ \\
\hline \multicolumn{7}{|c|}{ In ordinary conditions } \\
\hline K (critical) & {$[0.01 ; 0.05)$} & {$[0.01 ; 0.25)$} & {$[0.10 ; 0.20)$} & {$[0.10 ; 0.50)$} & {$[0.10 ; 0.20)$} \\
\hline H (low) & {$[0.05 ; 0.10)$} & {$[0.25 ; 0.50)$} & {$[0.20 ; 0.30)$} & {$[0.50 ; 0.80)$} & {$[0.20 ; 0.30)$} \\
\hline C (medium) & {$[0.10 ; 0.15)$} & {$[0.50 ; 0.75)$} & {$[0.30 ; 0.40)$} & {$[0.80 ; 1.10)$} & {$[0.30 ; 0.40)$} \\
\hline B (high) & {$[0.15 ; 0.20)$} & {$[0.75 ; 0.10)$} & {$[0.40 ; 0.50)$} & {$[1.10 ; 1.50)$} & {$[0.40 ; 0.60)$} \\
\hline \multicolumn{7}{|c|}{ In a crisis of the state of solvency } \\
\hline K (critical) & {$[0.00 ; 0.10)$} & {$[0.00 ; 0.50)$} & {$[0.00 ; 0.30)$} & {$[0.00 ; 0.80)$} & {$[0.00 ; 0.30)$} \\
\hline H (low) & {$[0.10 ; 0.15)$} & {$[0.50 ; 0.75)$} & {$[0.30 ; 0.40)$} & {$[0.80 ; 1.10)$} & {$[0.30 ; 0.40)$} \\
\hline C (medium) & {$[0.15 ; 0.20)$} & {$[0.75 ; 0.10)$} & {$[0.40 ; 0.50)$} & {$[1.10 ; 1.50)$} & {$[0.40 ; 0.60)$} \\
\hline B (high) & $\geq 0.20$ & $\geq 0.10$ & $\geq 0.50$ & $\geq 1.50$ & $\geq 0.56$ \\
\hline
\end{tabular}


To construct the criteria for the variables $x_{1}, x_{2}, x_{3}$ of model (18) segments should be taken, the right boundary of each of which will be the largest value of each variable, and the left - the smallest. These are divided into three equal parts, which will meet the fuzzy criteria - critical (K) low $(\mathrm{H})$, medium (C), high (B). It should be noted that the range of values of indicators used in assessing the individual credit risk of legal entities, with fuzzy criteria for variables differing from the range in times of financial instability due to the need to take into account the negative impact of risk factors on the solvency of participants-legal entities (users-borrowers) payment scoring (Table 7). The initial variable, as mentioned above, takes two values: 0 - the terms of the credit agreement are met (i.e., the individual credit risk of participants-legal entities (users-borrowers) minimal), 1- the terms of the credit agreement are not met (i.e., individual credit risk of participants-legal entities (users-borrowers) - maximum). To construct model (17) explicitly, linguistic assessments - "critical", "low", "medium", "high" with the help of dependence functions is formalized. These functions are defined in formula (19) [31]:

$$
\mu^{\tau}(\mathrm{x})=\frac{1}{1+\left(\frac{x-b}{c}\right)^{2}},
$$

where $\mu^{\tau}(\mathrm{x})$ is a number in the range [0,1], which characterizes the subjective parameter of compliance of the value $X$ with the fuzzy criterion $T$ (critical, low, medium, high); $b$ and $c$ are parameters of experts, which are grouped into experimental data; $b$ is the coordinate of the maximum of the function $\mu^{\tau}(\mathrm{x})$, and $\mu^{\tau}(\mathrm{x})=1, c$ is the coefficient of concentration - stretching function $\mu^{\tau}(\mathrm{x})$.

The fuzzy base of criteria in a compact form is given in Table 7, according to which the value of individual credit risk is minimal if the value of the asset mobility ratio and the cash flow ratio is "high": the asset mobility ratio is more than 0.5; cash flow ratio is more than 1.5. The instantaneous and current liquidity ratios should be "medium" (the value of the instantaneous liquidity ratio is in the range $[0.10-0.20)$, and the value of the current liquidity ratio is in the range $[0.25-0.50)$ ) or "high" (the value of the instantaneous liquidity ratio is more than 0.20 , and the value of the current liquidity ratio is more than 0.5 ).

Table 7. Compact view of the base of criteria for the coefficients of assessment of individual credit risk of participants-legal entities (users-borrowers) of card payment scoring of JSC CB "PRIVATBANK"

\begin{tabular}{|c|c|c|c|c|c|c|}
\hline $\mathrm{y}$ & № & $\mathrm{x}_{1}$ & $\mathrm{x}_{2}$ & $\mathrm{x}_{3}$ & $\mathrm{x}_{4}$ & $x_{5}$ \\
\hline \multirow{5}{*}{0} & 1 & $\mathrm{H}$ & $\mathrm{H}$ & $\mathrm{H}$ & K & B \\
\hline & 2 & $\mathrm{H}$ & $\mathrm{H}$ & B & $\mathrm{C}$ & K \\
\hline & 3 & $\mathrm{H}$ & $\mathrm{H}$ & B & B & K \\
\hline & 4 & $\mathrm{C}$ & $\mathrm{C}$ & B & $\mathrm{C}$ & $\mathrm{H}$ \\
\hline & 5 & $\mathrm{H}$ & $\mathrm{H}$ & $\mathrm{C}$ & $\mathrm{K}$ & $\mathrm{H}$ \\
\hline \multirow{7}{*}{1} & 6 & $\mathrm{C}$ & $\mathrm{C}$ & B & $\mathrm{C}$ & C \\
\hline & 7 & B & B & $\mathrm{H}$ & $\mathrm{H}$ & B \\
\hline & 8 & B & B & $\mathrm{C}$ & B & B \\
\hline & 9 & $\mathrm{H}$ & $\mathrm{H}$ & B & B & K \\
\hline & 10 & $\mathrm{C}$ & $\mathrm{C}$ & B & B & $\mathrm{C}$ \\
\hline & 11 & $\mathrm{H}$ & $\mathrm{H}$ & B & B & $\mathrm{H}$ \\
\hline & 12 & B & B & $\mathrm{H}$ & B & B \\
\hline
\end{tabular}


The level of individual credit risk increases significantly when the instantaneous and current liquidity ratios are "low" (the value of the instantaneous liquidity ratio does not reach 0.10 and the current liquidity ratio is less than 0.25 ). Thus, with the help of model (19), it is possible to estimate the impact of changes in financial indicators on the level of individual credit risk of participants-legal entities (users-borrowers) of card payment scoring of a banking institution, if initial values are successfully selected for parameter $\mathrm{s} b$ and $c$, the model will be more adequate to the experimental data. In cases when it is necessary to obtain a model (19) close enough to the experimental data, the model is adjusted. Model setting is the selection of parameter $\mathrm{s} b$ and $c$, which provide a minimum distance $\Delta$, between model and experimental data [31]. The value $\Delta$, which is the standard deviation of the theoretical and experimental outputs of the object, is used to assess the quality of the model settings. To adjust the model, a modification of the gradient method in the case of undifferentiated functions was used, the so-called $r-$ algorithm N. Shore [33], with accuracy $\varepsilon=$ 0.001 .Therefore, the above neuro-fuzzy model for assessing the individual credit risk of participants-legal entities (users-borrowers) of card payment scoring of a banking institution can be used for:

- the calculation of the forecast value of the level of financial condition for any set of financial ratios;

- the determination of optimal values of the borrower's financial indicators (i.e., such values for which the level of financial condition will be satisfactory);

- the analysis of trends in the impact of the values of financial indicators of participants-legal entities (users-borrowers) on the level of creditworthiness;

- determining the ranges of changes in each of the financial indicators at which the level of individual credit risk remains satisfactory;

- credit risk assessments for various banking products offered to corporate business.

\section{Conclusions}

To meet the conditions of the modern money market in a probabilistic crisis, the model can be supplemented by other indicators of the financial condition of corporate borrowers, which allows creating subsystems to support banking decisions on corporate business crediting on the basis of a fuzzy approach. Thus, a mandatory element of the mechanism of minimizing the risks of payment systems should be a flexible system of operational action and regulation of payment relations. In view of this, preventive measures for possible risks are: planning and design of a payment product, determining the level of its risk based on the assessment of the creditworthiness of participants and regular users of payment systems; control and monitoring of both specific, individual risks and payment portfolio risks.

In addition, banking institutions need to systematically improve methodological provisions and recommendations for assessing and minimizing the risks of payment systems, taking into account the dialectical combination of external (level of achievement of business objectives) and internal (achievement of economic performance) efficiency of the payment portfolio. These conditions determine the ability of banking institutions to ensure profitability and diversification of development through the selection and implementation of optimal strategies to achieve not only economic effect, but also adaptability and flexibility in the international payment system. Therefore, the complexity of the application of these elements and their comprehensive development forms an adaptive model of the mechanism of minimizing the risks of payment systems, which aimed at optimizing the operating activities of banking institutions in a market economy.

\section{REFERENCES}

[1] O.I. Baranovskyi. Stability of the banking system of Ukraine, Finance of Ukraine, No. 9, 75-87, 2007.

[2] Ya.V. Belinska, N.S. Kozii. Conceptual approaches to the stabilization of money circulation in a crisis, Economic Bulletin of the University, Vol. 29, No. 1, 274-81, 2016.

[3] N.E. Dieieva, V.V. Deleichuk. Mechanisms for attracting investments by issuers in the conditions of digital economy development, Young Scientist, Vol. 3, No. 55, 653-9, 2018.

[4] A.A. Hrytsenko. Development of forms of exchange, value and money, Osnova, Kyiv, 2015.

[5] B. Ivasiv. Modern interpretation of the concept of "electronic money" in the context of globalization of the financial market, Bulletin of Ternopil State Economic University, No. 5-2, 134-6, 2006.

[6] B.M. Vyshyvana, O.M. Tereshko. Oversight of payment and settlement systems: theoretical aspects and implementation mechanism in Ukraine, Scientific Bulletin of the International Humanities University. Economics and management, No. 11, 216-22, 2015.

[7] S.B. Yehorycheva. Modern aspects of classification of banking innovations, Scientific records of the National University “Ostroh Academy”, Economics, No. 22, 32-6, 2013.

[8] S.B. Yehorycheva. Financial mechanism for implementing banking innovation strategies, Scientific Bulletin of Poltava University of Economics and Trade, Series: "Economic Sciences”, Vol. 5, No.1, 183-8, 2010

[9] D.A. Balto. Payment systems and antitrust: can the opportunities for network competition be recognized? Federal Reserve Bank of St. Louis Review, Nov, 19-40, 1995.

[10] M. Bourreau, M. Verdier. Cooperation for innovation in 
payment systems: The case of mobile payments, Communications and Strategies, No. 79, 95-114, 2010.

[11] J.S. Cheney, R.M. Hunt, K. Jacob, R.D. Porter, B.J. Summers. The efficiency and integrity of payment card systems: industry views on the risks posed by data breaches, Economic Perspectives, Federal Reserve Bank of Chicago, Vol. 36, No. 4, 130-46, 2012

[12] R. Fujii-Rajani. FinTech developments in banking, insurance and FMIs, Reserve Bank of New Zealand Bulletin, No. 81, 3-40, 2018.

[13] M. Galbiati, K. Soramäki. An agent-based model of payment systems, Journal of Economic Dynamics and Control, Vol. 35, No. 6, 859-75, 2011.

[14] P. Haene. Retail payments in large-value payment systems - towards a coherent strategy, Incisive Media Limited, Vol. 5, No. 3, 11-5, 2011.

[15] T. Kokkola. The payment system: payments, securities and derivatives, and the role of the eurosystem, European Central Bank, Frankfurt am Main, 2010.

[16] C. Lagarde. Central banking and fintech: A brave new world, Innovations: technology, governance, globalization, MIT Press, Vol. 12, No. 1/2, 4-8, 2018.

[17] D. Laidler. The monetary economy and the economic crisis, Duke Department of Economics Research Paper, Online available from: http://dx.doi.org/10.2139/ssrn.1759503, 2011.

[18] A.E. Omarini. Fintech and the Future of the payment landscape: The mobile wallet ecosystem - a challenge for retail banks? International Journal of Financial Research, International Journal of Financial Research, Vol. 9, No. 4, 97-116, 2018

[19] R.S. Stinneford, L.H. Brown, C.M. Davis. Current developments in bank deposits and payment systems, The Business Lawyer, Vol. 65, No. 2, 629-43, 2010.

[20] B.J. Summers. Payment systems: design, governance and oversight, Central Banking Publications, London, 2012.

[21] V.P. Strakharchuk. Effective risk management systems in payment systems of developed economies, Bulletin of the Ukrainian Academy of Banking, Vol. 2, No. 7, 92-8, 1999.

[22] N.L. Ivashchuk. Application of quantitative methods in operational risk management, Bulletin of the National
University "Lviv Polytechnic": Problems of economy and management, No. 554, 255-61, 2006.

[23] O.M. Kalmykova. Functioning of the payment system of Ukraine and strategy of its development, Young scientist, Vol. 1, No. 16, 100-3, 2015.

[24] V.Ye. Bondarenko. Elements of subjective probability theory to assess the possibility of harmful effects and destructive actions in computer networks, Scientific Notes of the Ukrainian Research Institute of Communications, Vol. 4, No. 32,17-21, 2014

[25] L.A. Bondarenko. Risk-management of credit activity of a commercial bank, Vadym Hetman Kyiv National Economic University, Kyiv, 2007.

[26] O.D. Vovchak, H.Ye. Shparhalo, T.Ya. Andreikiv. Payment systems, Znannia, Kyiv, 2008.

[27] Activities of money transfer systems in Ukraine, Online available from:

https://bank.gov.ua/file/download?file=PS_oversayt_per_k osht_graf_2019.pdf, 2020.

[28] Analysis of the payment market of Ukraine, Online available from:

http://www.visnuk.com.ua/uploads/media/file/2019/02/25/ 6fd3ec2f45e8fd66a59efd6233679247ef934445.pdf, 2018.

[29] Cashless payments using payment terminals, Online available from: https://bank.gov.ua/news/all/bezgotivkovi-rozrahunki-z-vi koristannyam-platijnih-terminaliv-2019-rik, 2019.

[30] The World Bank Group, Online available from: https://www.worldbank.org/uk/country/ukraine, 2021.

[31] V.V. Bobyl, O.M. Prytomanova. Assessment of the financial condition of the borrower - a legal entity in a modern bank, Economics: problems of theory and practice, Vol. 1, No. 221, 172-84, 2006.

[32] L.I. Boikivska. Methods of bank risk assessment, Current problems of economic development of the region, Vol. 5, Online available from: http://base.dnsgb.com.ua/files/journal/Aktualni-problemy-r ozvytku-ekonomiky-regionu/2009_5_2/40.pdf, 2009.

[33] N.Z. Shor. Methods of minimization of non-differentiable functions and their applications, Scientific Opinion, Kyiv, 1979. 